\title{
PROMOTORES PÚBLICOS E PRIVADOS NO LEADER II: O CASO DAS NUTS DOURO E DAS REGIÕES AUTÓNOMAS DA MADEIRA E DOS AÇORES*
}

\author{
Francisco Diniz ${ }^{* *}$ \\ Fernanda Nogueira ${ }^{* * *}$
}

\begin{abstract}
A abordagem territorializada e integrada da implementação de politicas de desenvolvimento rural constitui a principal inovação introduzida na actual concepção da reformulação da politica agrícola comum, agora com um cari, cada vez mais rural e menos agrícola. A iniciativa comunitária LEADER é disso exemplo e tem sido apontada, embora com algumas limitações, como um êxito na mudança do status quo de muitas áreas rurais.

O objectivo deste Trabalho será o de analisar o que se passou até ao fim de 1999 nas zonas de intervenção do LEADER II que coincidem com as NUTS Douro, uma região periférica do continente português, e das Regiões Autónomas da Madeira e dos Açores que, dada a sua característica insular, detém um estatuto de ultra-perifericidade, prestando especial atenção ao papel assumido pelo investimento público e privado no processo de mudança para estes territórios.
\end{abstract}

Palavras-chave: Promotores públicos e privados, LEADER, regiões periféricas

\footnotetext{
** Professor Associado do Departamento de Economia e Sociologia da Universidade de Trás-os-Montes e Alto Douro.

*** Assistente do Departamento de Economia e Sociologia da Universidade de Trás-os-Montes e Alto Douro.
} 


\section{INTRODUÇÃO}

O carácter integrado e territorial da implementação de políticas de desenvolvimento em espaços rurais, aliado ao processo de globalização em curso, tem vindo a mudar o papel dos agentes públicos e privados intervenientes na mudança que se pretende operacionalizar.

Muitos são os autores que defendem a ideia de que todas as acções de desenvolvimento devem desencadear-se a partir das condições locais, ficando dependentes, por um lado, de factores de localização, da diversidade de sectores existentes na economia local, do nível das infra-estruturas sociais, da capacidade institucional e do grau de coesão social na região e, por outro, dos fins e dos objectivos propostos nas acções de desenvolvimento. $\mathrm{O}$ desenvolvimento não se desencadeia pela simples adopção de projectos mas é, isso sim, um processo que dá lugar à criação de produtos sociais, tais como a liderança local, a cultura empresarial e a acção inovadora que permitam às pessoas actuarem de forma concreta na descoberta de novas oportunidades. As acções de desenvolvimento local implicam uma abordagem multidimensional e multisectorial, criam as condições para o aparecimento de iniciativas baseadas numa abordagem de baixo para cima, com uma ampla participação no processo de planeamento por parte das populações locais.

Mas, e para que o desenvolvimento local, em meio rural, assuma uma natureza multidimensional e multisectorial, o programa que o orienta deverá ser integrado e integrador. Integrado porque os processos, projectos e acções que lhe dão corpo terão que conter todas as dimensões. Neste sentido o programa LEADER II, como instrumento de mudança de rumo das várias políticas de um espaço rural como o Douro e as Regiões Autónomas do Açores e da Madeira, é por nós analisado com o fim de ser verificado qual o papel dos agentes de mudança deste território na implementação do mesmo.

\section{O TERRITÓRIO RURAL}

Apesar da dificuldade de conceptualização do termo rural, pode dizer-se que, na essência, há três definições que entre si apresentam fortes inter-relações: a) definição sociocultural, que pressupõe que o 
comportamento e as atitudes diferem entre os habitantes de zonas de baixa densidade populacional (rurais) e as de forte densidade (urbanas), associando-se aos rurais valores tradicionais. Esta visão tem uma importante vertente antropológica; b) definição ocupacional, baseada na predominância de actividades económicas ligadas ao sector primário (agricultura, silvicultura, caça, pesca e indústrias extractivas). Esta distinção ocupacional deixou de ser determinante face à crescente integração dos agricultores nos mercados de trabalho não agrários. A pluriactividade é, hoje em dia, um elemento a ter presente no meio rural, de tal forma que a diferenciação ocupacional entre os rurais e os urbanos pode ser enganosa; c) definição ecológica, considera o rural como zonas de pequenos aglomerados com grandes espaços de paisagem aberta entre eles. Esta concepção implica uma definição de paisagem aberta e de grandes espaços.

Tanto para a União Europeia (UE) como para a Organização de Cooperação e Desenvolvimento Económico (OCDE), o mundo rural constitui um conjunto de regiões ou zonas com actividades diversas (agricultura, artesanato, pequena e média indústria, comércio e serviços entre outras), assente tanto em pequenos aglomerados, aldeias e pequenas cidades, como em espaços naturais e áreas cultivadas. Com base neste conceito, o mundo rural representa cerca de $80 \%$ do território comunitário e nele habitam e/ou desenvolvem a sua actividade mais de $50 \%$ da população total da UE.

A política agrária horizontal e o modelo global de desenvolvimento contribuíram para um aumento das disparidades regionais

Com a directiva para as Zonas de Montanha, a Comissão Europeia (CE) dá força a uma política estrutural de âmbito regional. As melhorias estruturais a introduzir consistem em redes de transporte interurbano, comunicações, electrificação, saneamentos, entre outros. A incapacidade das zonas rurais de disporem e manterem tecnologias concebidas para uma escala a que os residentes não podiam fazer face financeiramente esteve na origem do fracasso de muitos projectos. Os programas eram pensados e elaborados numa perspectiva de cima para baixo, não tendo as comunidades rurais qualquer protagonismo. $\mathrm{O}$ mundo rural continuou a agravar as suas disparidades, à medida que o processo de desenvolvimento se intensificava e a sociedade rural viu aumentar a sua desarticulação.

A segunda fase começa a dar os primeiros indícios de vida no início da década de 80 e assenta em pressupostos bem diferentes dos delineados pela Política Agrícola Comum (PAC) que, até então, tinha vigorado. No 
início da década de 80 , as zonas rurais podem ser qualificadas em três tipos: a) zonas em que o nível da população caiu tanto, que correm o risco de desertificação dentro de poucos anos, a menos que novas actividades para elas se transfiram ou que as Administrações Públicas as ajudem, subvencionando a conservação do meio ambiente (Zonas de Montanha ou Desfavorecidas); b) zonas que, apesar de não possuírem níveis significativos de desenvolvimento, conservam um volume de população que vê na agricultura não só uma actividade produtora de alimentos e matérias-primas, mas também uma garantia de manutenção do equilíbrio social e da estrutura económica, proporcionando um ambiente natural e são; c) zonas que encetaram um processo de diversificação das suas economias, onde houve uma certa industrialização, com empresas integradas em redes nacionais e multinacionais não exigentes em mão-de-obra especializada.

Todas estas formas têm algo em comum: a quebra do isolamento com o exterior e a perda de homogeneidade da sua população. Quanto à primeira, a evolução recente dos meios de comunicação e de transportes é a responsável pelo seu evoluir positivo. A segunda, a perda de homogeneidade, ficou a dever-se à introdução de novas actividades económicas e de novos residentes. Esta heterogeneidade favorece o eclodir de novos conflitos entre os grupos sociais dos rurais agrários com o dos rurais não agrários. Além disso, começa a ganhar terreno, tanto a nível nacional, como internacional, a opção pelo desenvolvimento sustentado, afectando ao mundo rural o papel de protector da Natureza e motor de actividades ligadas ao ócio e ao descanso.

A PAC, que durante 30 anos estimulou os aumentos de produção com as políticas de preços e mercados, para além de promover disparidades no rendimento, gerou excedentes de produtos como resultado dum excesso de oferta, o que fez aumentar o custo da armazenagem e destabilizou os mercados mundiais.

As áreas rurais são, portanto, a partir deste momento, analisadas considerando-se três tipos de população: a tradicional, ligada aos agricultores que vivem exclusivamente desta actividade, pela colocação dos produtos agrícolas no mercado; os que consideram a agricultura como segunda actividade e trabalham noutros sectores de actividade da economia local ou de centros urbanos próximos; e a população que não tem já qualquer laço com o sector agrícola e vive e/ou trabalha em áreas rurais e que, apesar de viver e/ou trabalhar em áreas rurais, pode não nada ter a ver com os hábitos de vida e a cultura da população rural. 
A compatibilização de novas e velhas conceptualizações acerca da difusão espacial das actividades económicas tem, como principal consequência, a perda da homogeneidade das áreas rurais. Pelo contrário, no contexto local, cada área rural tem a sua especificidade. A manutenção de actividades diversificadas em áreas rurais, a presença de agricultura de minifúndio, de formas simples de cooperação entre empresas de produção independente $\mathrm{e}$ individual ligadas ao artesanato não são mais consideradas obstáculos à modernização de áreas rurais, mas vistas como um capital humano que deve ser mantido em evolução permanente, ou cuja evolução deveria ser manipulada, (re)orientada e acelerada. A presença de população não agrícola tem um papel crucial no processo de diversificação e na incubação e circulação de um espírito empresarial. Por outro lado, o aparecimento de actividades não ligadas à exploração agrícola, em sentido estrito, não implica que tenham que ser, necessariamente, de carácter urbano.

De uma abordagem sectorial, há que evoluir para uma visão mais integradora, como se se estivesse a construir um puzzle de muitas peças, em que só se conhece a estrutura do todo quando todas as peças estão identificadas e encaixadas umas nas outras. Ao mundo rural estão afectas as actividades que menos valor acrescentado proporcionam e as que, concomitantemente, têm sido apontadas como as que menos contribuem para $\mathrm{o}$ processo de desenvolvimento. $\mathrm{O}$ anonimato a que, numa perspectiva de dentro para fora, tem sido votado o mundo rural, faz dele algo sem voz. Este silêncio em nada ajuda o lobbying e o protagonismo. O programa LEADER tem constituído, desde 1991, uma forma de alterar este estado de coisas.

\section{O LEADER II}

No LEADER II foram 48 as entidades apoiadas. Para além das 20 entidades já existentes no LEADER I foram ainda apoiadas mais 28 entidades, dando origem a mais 28 grupos GAL (Grupo de Acção Local), distribuídos agora por nove regiões: Entre Douro e Minho (3); Trás-os-Montes (3); Beira Litoral (5); Beira Interior (3); Ribatejo e Oeste (2); Alentejo (4); Algarve (1); Região Autónoma da Madeira (1); e Região Autónoma dos Açores (4) (DGPA, 1997 e 1999).

O orçamento atribuído aos Grupos, ainda sobre a forma de subvenção global, foi de aproximadamente 42 milhões de contos, sendo 25 milhões financiados pela UE a fundo perdido e 17 milhões de esforço financeiro 
nacional, os quais geriram o Programa nas respectivas ZI(s) (Zonas de Intervenção) num total de $81601 \mathrm{Km}^{2}$ (cobrindo agora $89 \%$ da superfície do território nacional, abrangendo cerca de 3470072 habitantes isto é $35 \%$ da população total do território).

Apesar do aumento quer da subvenção global, para um valor um pouco acima do dobro em relação ao LEADER I, quer da taxa de comparticipação (UE) de 52,9\% no LEADER I, para $60 \%$ no LEADER II, há a realçar o facto de que a cobertura do LEADER II, tanto em número de habitantes envolvidos como, sobretudo, em área de influência, mais que compensa aqueles valores.

Uma vez mais as diversas entidades (GAL - Grupo de Acção Local) geriram o programa e a respectiva subvenção, durante um período de 4 anos com a ajuda da referida Comissão Nacional de Gestão da Direcção Geral de Planeamento Agrícola (DGPA), nas 8 Medidas, ou áreas de actuação, sendo o objectivo da área 8 a cobertura dos custos de funcionamento das Entidades (GAL).

$\mathrm{O}$ carácter inovador dos investimentos LEADER II reside na programação e gestão feitas ao nível do território abrangido por parceiros institucionais, económicos e sociais reunidos no seio de um GAL e, simultaneamente, na rede que congrega todos os grupos em torno de uma "célula de animação". De forma a manter a inovação e a demonstratividade como critérios de elegibilidade, foram estruturadas, para o LEADER II, as seguintes áreas, ou medidas de actuação, e respectivas subáreas: Área 1- Apoio Técnico ao Desenvolvimento Rural; Área 2- Formação Profissional Específica e Apoios à Contratação; Área 3- Apoio à Diversificação das Actividades Económicas; Área 4Valorização e Comercialização das Produções Agrícolas, Silvícolas e Pesca Local; Área 5- Preservação e Valorização do Ambiente Natural e Qualidade de Vida; Área 6- Acções em Cooperação; Área 7- Outras; Área 8- Funcionameto do GAL.

O número total de projectos recebidos no LEADER II foi de 11608 , encontrando-se $6930(60 \%)$ aprovados, 3020 (26\%) concluídos e 519 $(4,4 \%)$ em overbooking. Isto à data do último relatório de execução disponível: Dezembro de 1999. Quanto ao número total de novos postos de trabalho já criados, ou a criar através dos projectos aprovados, este é de 3844 . 


\subsection{O Douro e o LEADER II}

A superfície territorial do Douro é de $4111,81 \mathrm{Km}^{2}$, representando 11 e $4 \%$ do total, respectivamente, em relação à Região Norte e ao Continente Português.

No que concerne à demografia constata-se que no Douro o decréscimo populacional, a fraca densidade populacional e o envelhecimento dos seus habitantes são as características comuns dignas de serem referidas quando se analisa o comportamento dos concelhos face às NUTS.

Quanto ao emprego, a região em análise tem um crescimento quase inexistente no que diz respeito à população activa no decénio 1981-1991, uma taxa de actividade e desemprego fortemente penalizantes para as mulheres e, por último, verifica-se uma bipolarização do emprego entre o sector primário e terciário que, no seu conjunto, empregam cerca de $80 \%$ da população activa. A terciarização da economia não pode deixar de constituir também uma característica a ter em linha de conta.

Um sector primário, predominantemente caracterizado por pequenas explorações fragmentadas, com produtores envelhecidos e com uma taxa de pluriactividade que indicia níveis de rendimento insuficiente na agricultura, constitui o retrato desta NUTS em termos económicos.

A situação geográfica contribui para o seu posicionamento em termos de desenvolvimento económico, face à Região Norte, ela própria também marginal em relação ao todo nacional. É uma região interior, de acessos difíceis coadjuvados com uma rede de transportes ineficiente, em que a agricultura desempenha o principal papel tanto em termos produtivos como na criação de riqueza e de emprego.

De seguida faremos uma análise mais detalhada da Região do Douro, para a qual foram seleccionadas as entidades ADRIMAG, DOLMEN, BEIRA DOURO, DOURO HISTÓRICO, DOURO SUPERIOR, CORANE e DESTEQUE, por forma a tentar verificar quais as diferenças mais relevantes ao nível dos seus investimentos LEADER II, quer tenham tido na sua base, promotores Públicos, quer Privados, quer Outros. Entenda-se, ao longo deste estudo, por "outros" todos os restantes promotores, de investimentos efectuados no âmbito do LEADER II. São exemplos, entre outros, as cooperativas, as associações e as organizações não governamentais. 


\section{Quadro 1}

MONTANTES DE INVESTIMENTO E RESPECTIVAS TAXAS DE EXECUÇÃO POR ENTIDADE E NACIONAIS

\begin{tabular}{|c|c|c|c|}
\hline ENTIDADES & $\begin{array}{c}\text { INVESTIMENTO } \\
\text { APROVADO }\end{array}$ & $\begin{array}{l}\text { INVESTIMENTO } \\
\text { APLICADO (1999) }\end{array}$ & $\begin{array}{c}\text { TAXA DE } \\
\text { EXECUÇÃO (1999) }\end{array}$ \\
\hline ADRIMAG & 1098980 & 599873 & $55 \%$ \\
\hline DOLMEN & 635318 & 411691 & $65 \%$ \\
\hline BEIRA DOURO & 802373 & 353709 & $44 \%$ \\
\hline DOURO HISTÓRICO & 1121995 & 569962 & $51 \%$ \\
\hline DOURO SUPERIOR & 798485 & 614086 & $77 \%$ \\
\hline CORANE & 721579 & 422290 & $59 \%$ \\
\hline DESTEQUE & 1144908 & 837362 & $73 \%$ \\
\hline TOTAL DA REGIÃO & 6323638 & 3808973 & $60 \%$ \\
\hline TOTAL NACIONAL & 42056351 & 24130011 & $57 \%$ \\
\hline
\end{tabular}

Fonte: Elaborado com base nos relatórios LEADER, 1997 e 1999.

Note-se que a taxa de execução financeira global a nível nacional é, nesta data, de $57 \%$ para o investimento total e de $60 \%$ para o total da Região em análise. De realçar são, também, as taxas de execução das entidades DOLMEN, DOURO SUPERIOR e DESTEQUE, todas com taxas de execução acima da média da Nacional e da Região em análise. Apenas uma destas entidades é gestora do programa LEADER desde o início (DESTEQUE). As restantes surgem com o LEADER II em 1994.

Quanto à entidade ADRIMAG, angariou 145 projectos, perfazendo estes um investimento total de 1098980 contos, tendo sido 65\% financiados pela EU a fundo perdido. A medida de actuação preferida, por esta entidade, foi a medida 5 - Preservação e Valorização do Ambiente Natural e Qualidade de Vida. 
Figura 1

INVESTIMENTO ADRIMAG, PÚBLICO E PRIVADO 1999

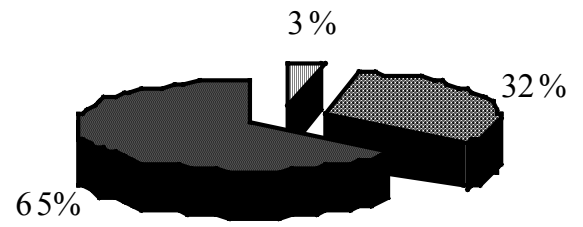

\author{
IIII Investimento Público \\ Investimen to Privado \\ Investimen to UE
}

Fonte: Elaborado com base nos relatórios LEADER, 1999.

Dos investimentos promovidos por esta entidade apraz-nos referir que, apesar de 43,5\% dos projectos terem tido como promotores entidades públicas, o esforço financeiro dos mesmos fica-se pelos $3 \%$, ficando o restante a cargo da UE e dos privados.

A BEIRA DOURO angariou 134 projectos, totalizando estes um investimento total de 802373 contos, tendo sido 53\% financiados pela UE a fundo perdido. A medida de actuação preferida, por esta entidade, foi a medida 1 - Apoio Técnico ao Desenvolvimento Rural.

Figura 2

INVESTIMENTO BEIRADOURO UE, PÚBLICO E PRIVADO 1999

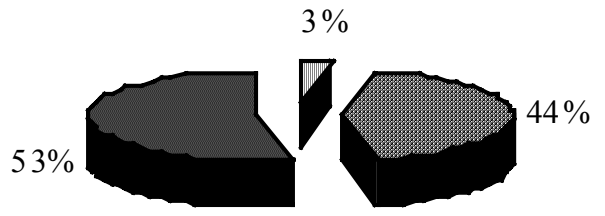

IIIII Investimento Público

- Investimento Privado

In vestimento UE

Fonte: Elaborado com base nos relatórios LEADER, 1999. 
Dos investimentos promovidos por esta entidade há a salientar que, apesar de $44 \%$ dos projectos terem tido como promotores entidades públicas, o esforço financeiro dos mesmos fica-se pelos $3 \%$, fícando o restante a cargo da UE e dos privados.

A CORANE angariou 60 projectos, completando estes um investimento total de 721579 contos, tendo sido 63\% financiados pela EU a fundo perdido. A medida de actuação preferida, por esta entidade, foi a medida 1 - Apoio Técnico ao Desenvolvimento Rural.

Figura 3

INVESTIMENTO CORANE UE, PÚBLICO E PRIVADO 1999

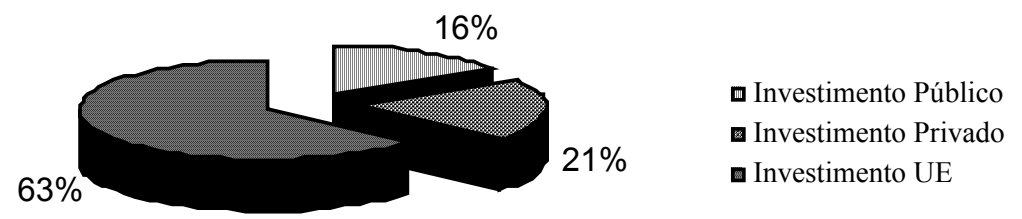

Fonte: Elaborado com base nos relatórios LEADER, 1999.

Dos investimentos promovidos por esta entidade saliente-se que, apesar de $30 \%$ dos projectos terem tido como promotores entidades públicas o esforço financeiro dos mesmos fica-se pelos $16 \%$, ficando o restante a cargo da UE e dos privados.

A DESTEQUE angariou 139 projectos, atingindo estes um investimento total de 1144908 contos, tendo sido 65\% financiados pela UE a fundo perdido. A medida de actuação preferida, por esta entidade, foi a medida 3 - Apoio à Diversificação das Actividades Económicas. 
Figura 4

INVESTIMENTO DESTEQUE UE, PÚBLICO E PRIVADO 1999

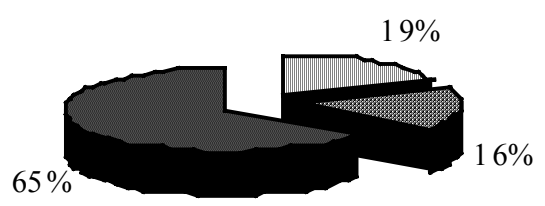

||II|| Inv estimen to P úblico

Inv estimen to P rivado

Inv estim en to UE

Fonte: Elaborado com base nos relatórios LEADER, 1999.

Dos investimentos promovidos por esta entidade destaque-se que, apesar de $36,8 \%$ dos projectos terem tido como promotores entidades públicas, o esforço financeiro dos mesmos situa-se nos 19\%, ficando o restante a cargo da UE e dos privados.

A DOLMEN angariou 75 projectos, somando estes um investimento total de 635318 contos, tendo sido $61 \%$ financiados pela UE a fundo perdido. A medida de actuação preferida, por esta entidade, foi a medida 3 - Apoio à Diversificação das Actividades Económicas.

Figura 5

INVESTIMENTO DOLMEN UE, PÚBLICO E PRIVADO 1999

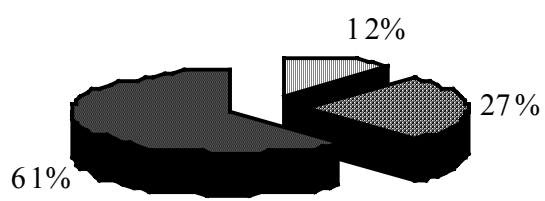

IIIII Investimento Públ ico

Investimento Privado

Investimento UE

Fonte: Elaborado com base nos relatórios LEADER, 1999. 
Dos investimentos promovidos por esta entidade recorde-se que, apesar de $25,3 \%$ dos projectos terem tido como promotores entidades públicas, o esforço financeiro dos mesmos fica-se pelos $12 \%$, ficando o restante a cargo da UE e dos privados.

A DOURO HISTÓRICO angariou 60 projectos perfazendo estes um investimento total de 1121995 contos, tendo sido 62\% financiados pela UE a fundo perdido. A medida de actuação preferida, por esta entidade, foi a medida 3 - Apoio à Diversificação das Actividades Económicas

\section{Figura 6 \\ INVESTIMENTO DOURO HISTÓRICO UE, PÚBLICO \\ E PRIVADO 1999}

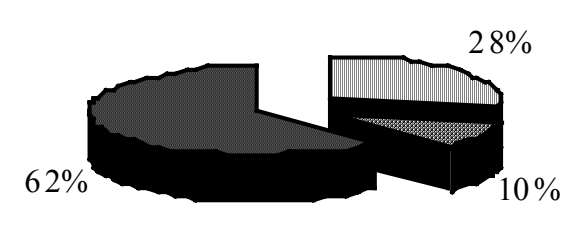

IIIII In vestimento Público

- Investimento Priv ado

Investimento UE

Fonte: Elaborado com base nos relatórios LEADER, 1999.

Dos investimentos promovidos por esta entidade recordemos que, apesar de $48,3 \%$ dos projectos terem tido como promotores entidades públicas, o esforço financeiro dos mesmos atinge $28 \%$, ficando o restante a cargo da UE e dos privados.

A DOURO SUPERIOR angariou 87 projectos perfazendo estes um investimento total de 798485 contos, tendo sido $60 \%$ financiados pela EU a fundo perdido. A medida de actuação preferida, por esta entidade, foi a medida 3 - Apoio à Diversificação das Actividades Económicas. 


\section{Figura 7 \\ INVESTIMENTO DOURO SUPERIOR UE, PÚBLICO \\ E PRIVADO 1999}

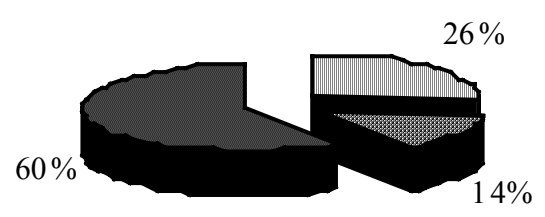

IIIIII Investimento Público

Investimento Priv ado

Investimento UE

Fonte: Elaborado com base nos relatórios LEADER, 1999.

Dos investimentos promovidos por esta entidade lembra-se que, apesar de $44,8 \%$ dos projectos terem tido como promotores entidades públicas, o esforço financeiro dos mesmos fica-se pelos $26 \%$, ficando o restante a cargo da UE e dos privados.

\subsection{A Região Autónoma da Madeira e o LEADER II}

É uma região com $600 \mathrm{~km}^{2}$ de superfície, de vales e montanhas, ultraperiférica que está a cerca de $1400 \mathrm{~km}$ do Continente e a cerca de $690 \mathrm{~km}$ da costa ocidental de África. A actividade agrícola é caracterizada por pequenas explorações de carácter familiar. É uma região com fortes potencialidades para o turismo e divulgação do artesanato local. No entanto, constata-se um nível de instrução insuficiente ( $28 \%$ de analfabetos), falta de capacidade de investimentos privados, uma organização deficiente, uma mecanização limitada pela orografia da zona, uma elevada dependência do exterior em produtos essenciais e a tendência para o êxodo rural, sobretudo nos jovens.

A sua população é de 90825 habitantes, sendo que 50\% da população tem menos de 25 anos e 10\% mais de 64 anos. Da população activa desta Região $15 \%$ encontram-se na agricultura, $33 \%$ na indústria e $52 \%$ nos serviços. A taxa de desemprego, em 1992, era de 4\%. 
A ACAPORAMA é uma associação de Casas do Povo da Região da Madeira. Propondo-se continuar o trabalho das suas associadas, esta instituição direcciona a sua estratégia de actuação para a promoção, dignificação, valorização e vulgarização das artes e costumes locais, com vista ao desenvolvimento socioeconómico da região. Assim, a estratégia adoptada passa pelo envolvimento permanente da rede das Casas do Povo, prevendo no entanto a participação de outros agentes locais, económicos e socioprofissionais. $\mathrm{Da}$ sua estratégia de actuação beneficiarão empresários, agricultores, artesãos e industriais.

No LEADER II a entidade ACOPORAMA reduz a sua área de intervenção, passando a sua ZI a abranger $283 \mathrm{Km}^{2}$ com 5 concelhos e 21 freguesias, tendo uma densidade populacional por $\mathrm{Km}^{2}$ de 349 habitantes. Da população activa da ZI 14\% trabalha no sector primário, $40 \%$ no secundário e $46 \%$ no sector terciário, sendo a taxa de desemprego de aproximadamente $8 \%$.

Esta perda de território (do LEADER I para o LEADER II) verificou-se devido ao aparecimento de uma outra entidade, a ADRAMA.

A ADRAMA veio cobrir uma ZI de $477 \mathrm{Km}^{2}$ (6 concelhos e 28 freguesias), com uma densidade populacional por $\mathrm{Km}^{2}$ de118 habitantes. Do total da população activa, nesta ZI, $41 \%$ encontra-se no sector primário, $30 \%$ no sector secundário e $29 \%$ no sector terciário. A ZI em causa apresenta, no ano de início do programa, uma taxa de desemprego de $29 \%$.

Desta primeira análise, dois aspectos são de realçar: primeiro, a Região da Madeira passa, do LEADER I para o LEADER II, de uma ZI total de $600 \mathrm{Km}^{2}$ para $760 \mathrm{Km}^{2}$, cobrindo assim o LEADER II mais 160 $\mathrm{Km}^{2}$ do que o LEADER I. Somos levados a concluir que o surgimento da ADRAMA veio cobrir a área mais rural da Ilha. Isto porque a sua ZI apresenta $41 \%$ da população activa no sector primário (a ACOPORAMA detém, no mesmo sector, $14 \%$ da sua população activa) e é também a mais deficitária em termos populacionais, com uma densidade populacional de 118 habitantes por $\mathrm{Km}^{2}$ (a ACOPORAMA apresenta uma densidade populacional de 349 habitantes por $\mathrm{Km}^{2}$ ) e, por último, apresenta uma taxa de desemprego de $29 \%$. 


\section{Quadro 2 \\ MONTANTES DE INVESTIMENTO E RESPECTIVAS TAXAS DE EXECUÇÃO POR ENTIDADE E NACIONAIS}

\begin{tabular}{|l|r|r|c|}
\hline \multicolumn{1}{|c|}{ ENTIDADES } & $\begin{array}{c}\text { INVESTIMENTO } \\
\text { APROVADO }\end{array}$ & $\begin{array}{c}\text { INVESTIMENTO } \\
\text { APLICADO (1999) }\end{array}$ & $\begin{array}{c}\text { TAXA DE } \\
\text { EXECUÇÃO (1999) }\end{array}$ \\
\hline ACAPORAMA & 651497 & 296203 & $45 \%$ \\
ADRAMA & 654390 & 395696 & $60 \%$ \\
\hline TOTAL DA REGIÃO & $\mathbf{1 2 0 5 8 8 7}$ & $\mathbf{6 9 1 8 9 9}$ & $\mathbf{5 3 \%}$ \\
\hline TOTAL NACIONAL & $\mathbf{4 2 0 5 6 3 5 1}$ & $\mathbf{2 4 1 3 0 0 1 1}$ & $\mathbf{5 7 \%}$ \\
\hline
\end{tabular}

Fonte: Elaborado com base nos relatórios LEADER, 1997 e 1999.

Na Região Autónoma da Madeira, as entidades GAL ACAPORAMA e ADRAMA apresentam um investimento aprovado de 651497 contos e 654390 respectivamente, obtendo ambas uma comparticipação comunitária de aproximadamente 325000 contos. No entanto, é a ADRAMA a entidade que, maior taxa de execução apresenta, até à data, $(60 \%)$.

Outra constatação, de alguma relevância, é o número de projectos recebidos pelas duas entidades. Contrariamente àquilo que se podia esperar, pelas características das ZI(s) em causa, é a ADRAMA que maior número de projectos recebe. Dos 109 projectos recebidos estão já concluídos pela ACAPORAMA 24 (22\%), sendo estes valores para a ADRAMA de 124 e 36 (29\%), respectivamente.

A ACAPORAMA angariou, assim, 109 projectos perfazendo estes um investimento total de 651497 contos, tendo sido $65 \%$ financiados pela UE a fundo perdido. A medida de actuação preferida, por esta entidade, foi a medida 3 - Apoio à Diversificação das Actividades Económicas. 
Figura 8

INVESTIMENTO ACAPORAMA UE, PÚBLICO E PRIVADO 1999
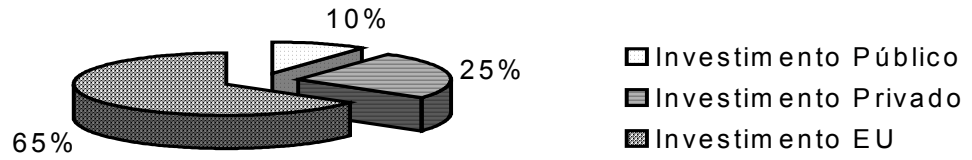

Fonte: Elaborado com base nos relatórios LEADER, 1999.

A ADRAMA angariou, assim, 124 projectos perfazendo estes um investimento total de 654390 contos, tendo sido $65 \%$ financiados pela UE a fundo perdido. A medida de actuação preferida, por esta entidade, foi também a medida 3 - Apoio à Diversificação das Actividades Económicas.

Figura 9

INVESTIMENTO ADRAMA UE, PÚBLICO E PRIVADO 1999

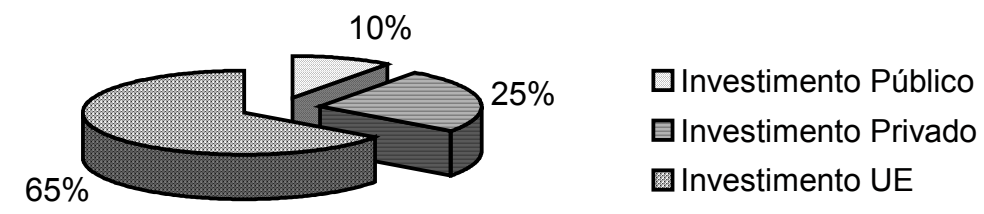

Fonte: Elaborado com base nos relatórios LEADER, 1999. 


\subsection{A região Autónoma dos Açores e o LEADER II}

A Região Autónoma dos Açores foi contemplada com a aprovação de quatro PAL(s) oriundos da candidatura das quatro entidades já referidas, cobrindo, desta forma, uma ZI total de $2333 \mathrm{Km}^{2}$ em 19 concelhos e 150 freguesias. O orçamento LEADER global, para a região, foi de 2342044 contos sendo 1300000 contos de comparticipação UE e o restante (1 042 044 contos) de esforço local.

Desagregadamente, isto é, por entidades, as ZI(s) caracterizam-se, sucintamente, da seguinte forma:

- A ADELIAÇOR cobrindo uma ZI de $1025 \mathrm{Km}^{2}$ ( 9 concelhos e 53 freguesias) com uma densidade populacional de 43,8 habitantes por $\mathrm{Km}^{2}$. Da sua população activa $28 \%$ trabalha no sector primário, $23 \%$ no secundário e $49 \%$ nos serviços. Esta ZI apresenta uma taxa de desemprego de $2,2 \%$;

- A ARDE, abrangendo 2 concelhos e 27 freguesias cobre, com a sua ZI, $329 \mathrm{Km}^{2}$ com uma densidade populacional de 206,2 habitantes por $\mathrm{Km}^{2}$. Quanto à sua população activa, esta está em $11 \%$ no sector primário, $21 \%$ no secundário e $67 \%$ nos serviços. A taxa de desemprego, nesta ZI, é de 3,2\%.

- A ASDEPR apresenta uma ZI de $515 \mathrm{Km}^{2}$, com 5 concelhos e 37 freguesias e uma densidade populacional de 124,2 habitantes por $\mathrm{Km}^{2}$. A população activa, nesta ZI, é de $31 \%$ no sector primário, $26 \%$ no secundário e $44 \%$ no terciário, sendo a sua taxa de desemprego de 3,3\%.

- Por último a GRATER, com uma ZI de $461 \mathrm{Km}^{2}$, abrangendo 3 concelhos e 33 freguesias e uma densidade populacional de 132,2 habitantes por $\mathrm{Km}^{2}$. Nesta ZI a população activa está em $16 \%$ no sector primário, $21 \%$ no secundário e $63 \%$ no terciário. A taxa de desemprego é de $4,1 \%$.

De destacar, desta pequena caracterização, a ZI da entidade ADELIAÇOR que, sendo a ZI que menor população apresenta, é a que detém maior superfície territorial, sensivelmente o dobro das suas parceiras, e a maior dispersão em termos de Ilhas (5), podendo este facto, de alguma forma, comprometer a execução do programa.

De referir também que, à excepção da entidade ASDEPR, a qual detém toda a sua ZI numa só Ilha (S. Miguel), todas as outras entidades repartem a sua ZI por mais do que uma Ilha: ARDE 2 ilhas (S. Miguel e 
$\mathrm{St}^{\mathrm{a}}$ Maria); ADELIAÇOR, como já referimos, 5 ilhas (Corvo, Flores, Faial, Pico e S. Jorge); e GRATER 2 ilhas (Graciosa e Terceira).

\section{Quadro 3}

MONTANTES DE INVESTIMENTO E RESPECTIVAS

TAXAS DE EXECUÇÃO POR ENTIDADE E NACIONAIS

\begin{tabular}{|l|c|c|c|}
\hline \multicolumn{1}{|c|}{ ENTIDADES } & $\begin{array}{c}\text { INVESTIMENTO } \\
\text { APROVADO }\end{array}$ & $\begin{array}{c}\text { INVESTIMENTO } \\
\text { APLICADO (1999) }\end{array}$ & $\begin{array}{c}\text { TAXA DE } \\
\text { EXECUÇÃO (1999) }\end{array}$ \\
\hline ADELIAÇOR & 769033 & 332191 & $48 \%$ \\
ARDE & 798370 & 355099 & $44 \%$ \\
ASDEPR & 766659 & 354099 & $47 \%$ \\
GRATER & 947142 & 540601 & $61 \%$ \\
\hline TOTAL DA REGIÃO & $\mathbf{3 2 8 1 2 0 4}$ & $\mathbf{1 0 9 5 9 9 0}$ & $\mathbf{5 0 \%}$ \\
\hline TOTAL NACIONAL & $\mathbf{4 2 ~ 0 5 6 ~ 3 5 1}$ & $\mathbf{2 4 1 3 0 0 1 1}$ & $\mathbf{5 7 \%}$ \\
\hline
\end{tabular}

Fonte: Elaborado com base nos relatórios LEADER, 1997 e 1999.

Na Região Autónoma dos Açores, o investimento aprovado vai dos 766659 contos aos 947142 contos, o que, conjuntamente com uma comparticipação UE constante, conduz a taxas de comparticipação comunitária de $52 \%$ a $62 \%$. A taxa de execução, à data do último relatório (1999), vai de 44\% (ARDE) a 61\% (GRATER). As restantes entidades têm uma taxa de execução na ordem dos $47 \%, 48 \%$.

Outra constatação, de alguma relevância, é o número de projectos recebidos e concluídos pelas entidades. Apesar da GRATER ser a entidade com maior número de projectos recebidos, apresenta a menor taxa de projectos concluídos (17\%). A ADELIAÇOR apresenta a maior percentagem de projectos concluídos (33\%).

A ADELIAÇOR angariou, assim, 227 projectos, perfazendo estes um investimento total de 769033 contos, tendo sido 55\% financiados pela UE a fundo perdido. A medida de actuação preferida, por esta entidade, foi a medida 3 - Apoio à Diversificação das Actividades Económicas.

Figura 10 
INVESTIMENTO ADELIAÇOR UE, PÚBLICO E PRIVADO 1999

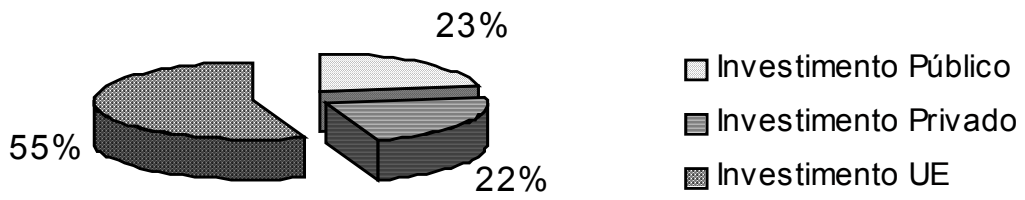

Fonte: Elaborado com base nos relatórios LEADER, 1999.

A ARDE angariou, assim, 218 projectos, perfazendo estes um investimento total de 798.370 contos, tendo sido $53 \%$ financiados pela UE a fundo perdido. A medida de actuação preferida, por esta entidade, foi a medida 3 - Apoio à Diversificação das Actividades Económicas.

\section{Figura 11}

INVESTIMENTO ARDE UE, PÚBLICO E PRIVADO 1999

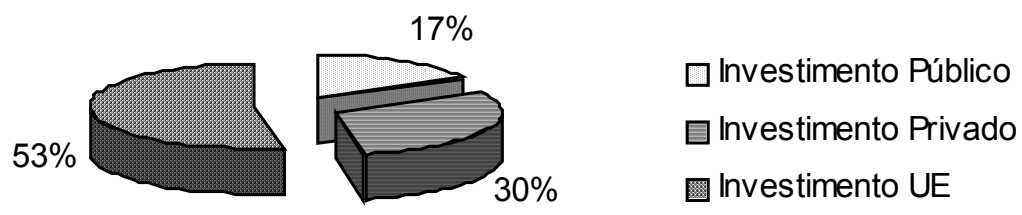

Fonte: Elaborado com base nos relatórios LEADER, 1999.

A ASDEPR angariou, assim, 79 projectos perfazendo estes um investimento total de 766.659 contos, tendo sido 54\% financiados pela UE a fundo perdido. A medida de actuação preferida, por esta entidade, foi a medida 3 - Apoio à Diversificação das Actividades Económicas. 
Figura 12

INVESTIMENTO ASDEPR UE, PÚBLICO E PRIVADO 1999

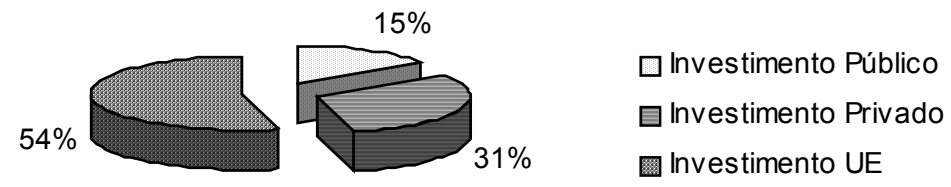

Fonte: Elaborado com base nos relatórios LEADER, 1999.

A GRATER angariou, assim, 369 projectos, totalizando estes um investimento total de 947142 contos, tendo sido $48 \%$ financiados pela UE a fundo perdido. A medida de actuação preferida, por esta entidade, foi a medida 3 - Apoio à Diversificação das Actividades Económicas.

Figura 13

INVESTIMENTO GRATER UE, PÚBLICO E PRIVADO 1999

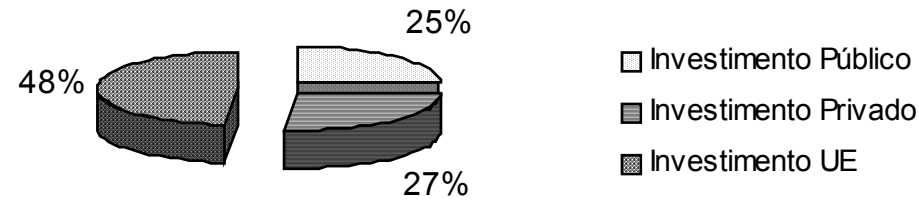

Fonte: Elaborado com base nos relatórios LEADER, 1999.

\section{CONSIDERAÇÕES FINAIS}

Sendo o LEADER um programa que, como a sua própria designação sugere, pretende promover a Ligação Entre Acções do Desenvolvimento das Economias Rurais, verifica-se que o sector público continua a ter um 
papel determinante como agente de mudança. A iniciativa privada mantém-se em estado de letargia, apesar dos incentivos postos à sua disposição pelo programa LEADER II.

Para o todo do território Nacional o investimento LEADER II, até 1999, foi em $60 \%$ financiado pela UE, cabendo $15 \%$ e $25 \%$, respectivamente, aos promotores públicos e privados. Ao nível da NUT Douro o território conseguiu uma ligeira vantagem no financiamento a cargo da UE $(62 \%)$. Uma vez que o esforço público está ao mesmo nível do que acontece para o todo Nacional, é o esforço privado que fica um pouco abaixo (23\%).

A entidade com maior peso no número de projectos implementados por promotores públicos é a DOURO HISTÓRICO $(48,3 \%)$. No entanto, o montante investido nestes projectos é apenas de $28 \%$, o que nos leva a concluir que o sector público assegura na ZI desta entidade projectos de pequena dimensão. Esta conclusão é também válida para a entidade DOLMEN que apresenta a maior fatia do número de projectos privados (64\%) que se materializam em $27 \%$ do montante investido.

Quanto às Regiões Autónomas da Madeira e dos Açores, é no Açores que o investimento público apresenta as maiores percentagens. Em contraposição, a Madeira fica-se pelos $10 \%$. No que diz respeito ao investimento privado a Madeira apresenta uma taxa de $25 \%$ do total, enquanto que os Açores apresentam 27,5\%. Também as taxa de comparticipação UE são distintas nestas regiões a Madeira consegue uma taxa de comparticipação de $65 \%$ enquanto que a Região dos Açores se fica nos $53 \%$.

Analisando, agora, o investimento por habitante das ZI(s), o valor mais elevado encontra-se no Continente (10,5 contos/habitante), situando-se este valor um pouco abaixo dos 4,5 contos/habitante no caso de ambas as regiões insulares e da própria região da NUT Douro $(6,3$ contos/habitante). O esforço local de cada habitante é de 36\% para o caso do Continente e de $65 \%, 44 \%$ e $40 \%$ para o caso das ZI(s) LEADER das Regiões Autónomas da Madeira, dos Açores e da NUT Douro, respectivamente.

O estatuto de ultraperiférico nem sempre se traduz em menor esforço local, o que no caso da Região Autónoma da Madeira só acontece devido à estratégia minimalista adoptada, aquando da programação do investimento total, por parte dos GAL.

Por fim, e ainda com base no relatório de Execução Anual de 1999 do LEADER II, podemos realçar como pontos fortes:

- diversificação das actividades; 
- cooperação inter-regional com entidades LEADER do continente e intra-regional com as restantes entidades insulares;

- forte incremento do número de projectos;

- envolvimento da população, nomeadamente em actividades de índole cultural;

- integração em redes de comércio electrónico;

- criação de espaços para a comercialização de produtos rurais.

Se passarmos agora para os pontos fracos há a referir os seguintes:

- burocracia;

- baixa disponibilidade financeira face ao elevado número de candidaturas de projectos;

- necessidade de dotação dos GAL com meios técnicos e humanos.

Toda esta análise poderá ser refinada aquando da publicação, para breve, esperamos, do Relatório de Execução final do LEADER II, o qual contemplará a finalização de todos os investimentos programados em 1994.

\section{NOTA}

* Apresentado nas III Jornadas do ICETA-UTAD Vila Real, Novembro de 2001.

\section{BIBLIOGRAFIA}

BANDARRA, N. J. (1995). "Spécificité du Développement Rural". Économie Rurale, $n^{\circ} 225$, pp. 33-36.

BRYDEN, J. (1994). "Prospects for Rural Areas in an Enlarged Europe". Journal of Rural Studies, Vol. 10, nº 4, pp. 387-394.

CAMACHO, A. Crujeira, C. Lucena, J. Pinho, I. (1982), Gestão Pública: uma abordagem integrada, Livros Técnicos e Científicos, Lda

CHASE, Colin (1989). A Tomada de Decisão, Lisboa, Gradiva.

COURLET, C. (1995). "L'industrialisation en Milieu Rural". Économie Rurale, no 225 , pp. 12-14. 
CRISTOVÃO, A. (1986). Farmers' Participation in the Development of Agricultural Extension Programs in One County in Trás-os-Montes, Northeastern Portugal (Doctoral dissertation, University of Wisconsin-Madison). Dissertation Abstracts International.

DENHARDT, Robert (1990). "Public Administration Theory" in Naomi Lynn \& Aaron Wildavsky (orgs), Public Administration Theory - The State of the Discipline, London, Chatham House Publishers.

DGPA, (1996). Relatório de Execução Anual, Volumes I a VIII. Lisboa. C.N.G.

DGPA, (1997). Relatório de Execução Anual, Volumes I a VIII. Lisboa. C.N.G.

DGPA, (1998). Relatório de Execução Anual, Volumes I a VIII. Lisboa. C.N.G.

DGPA, (1999). Relatório de Execução Anual, Volumes I a VIII. Lisboa. C.N.G.

DINIZ, F.J.L.S. (1999). Desenvolvimento Rural - Que Perspectivas. O Caso do Alto Trás-os-Montes e Douro, Fundação Rei Afonso Henriques, Zamora.

DRUCKER, Peter F. (1976). Uma Era de Descontinuidade - Orientações para uma Sociedade em Mudança. Rio de Janeiro: Zahar Editores.

DRUCKER, Peter F. (1980). Administração em Tempos Turbulentos, São Paulo, Livraria Pioneira Editora.

FIEDLING, A. J. (1994). "Contra-urbanização: ameaça ou benção?" in PINDER, D. Europa Ocidental: Desafios e Mudanças, Cap 14, Celta Editora, Oeiras, pp. 295-313.

GERRY, C. \& NOGUEIRA, F. (2000). "Reflexões Acerca da Aplicabilidade à Administração Pública de Inovações Recentes na Gestão de Empresas Privadas", in $2^{\circ}$ Encontro INA Moderna Gestão Pública - Dos Meios aos Resultados, Lisboa, Fundação Gulbenkian.

GREFFE, X. (1995). "Aménagement du Territoire ou Aménagement du Milieu". Économie Rurale, $\mathrm{n}^{\circ} 225$, pp. 4-7.

GUGLIELMI, M. (1995). "Vers de nouvelles fonctions de l'agriculture dans l'espace?". Economie Rurale, no 209, pp. 17-21.

ILBERY, B.W. (1994). "O Desafio do Abandono das Terras", in PINDER, D., Europa Ocidental: Desafios e Mudanças, Cap 13, Celta Editora, Oeiras, pp. 275-293.

MOE, Ronald C. (1994). "The 'Reinventing Government' Exercise: Misinterpreting the Problem, Misjudging the Consequences", in Public Administration Review, 54:111-22.

OSBORNE, David \& Gaebler, Ted (1994). "Reinventando o Governo: Como o Espírito Empreendedor está transformando o sector público", Brasília, MacGraw Hill. Comunicação.

PERRIER-CORNET, P. e Capt, D. (1995). "Les Agriculteirs Face à la Nouvelle PAC: Quelles perspectives pour quels territoires?". Économie Rurale, $\mathrm{n}^{\mathrm{o}} 225$, pp. 22-27. 
PFEFFER, J. (1994). Gerir com Poder. Politicas e influências nas Organizações, Venda Nova, Bertrand Editora.

SARACENO, E. (1994). "Recent Trends in Rural Development Conceptualization". Journal of Rural Studies, Vol. 10, no 4, pp. 321-330.

SFEZ, Lucien (1990). Critica da Decisão, Lisboa, D. Quixote.

SIMON, A. Herbert (1983). Administration et Processus de Décision, Paris, Gestion Economica.

WOODURFFE, B.J. (1994). "Conservação e Paisagem Rural" in PINDER, D., Europa Ocidental: Desafios e Mudanças, Cap 16, Celta Editora, Oeiras, pp. 337-359. 